\title{
Traditional Ecological Knowledge and Climate Change Adaptation: The Sa'ban experience
}

\author{
Nadzirah Hosen ${ }^{1}$, Hitoshi Nakamura², Amran Hamzah³ \\ ${ }^{1}$ Graduate School of Engineering and Science, \\ 2Department of Planning, Architecture and Environment Systems, \\ Shibaura Institute of Technology, Japan \\ ${ }^{3}$ Faculty of Built Environment and Surveying, \\ Universiti Teknologi Malaysia, Malaysia \\ na17506@shibaura-it.ac.jp, nakamu-h@shibaura-it.ac.jp, merang@utm.my
}

\begin{abstract}
Indigenous people often rely on natural resources for their livelihoods. This reliance increases their vulnerability towards the impacts of climate change, and coping with increased climate variability is a significant challenge for such communities. This research, conducted among the Sa'ban tribe of Long Banga in interior Sarawak, Malaysia, explored observations of local climate change, climate change impacts and tribal adaptation strategies. The results show that drought, wildfires and uncertain weather conditions are the Sa'ban's primary concerns. However, the tribe have demonstrated their adaptation strategies through the use of traditional ecological knowledge (TEK).

Keywords: indigenous people, traditional ecological knowledge, adaptive capacity, climate change adaptation

eISSN 2514-7528 @2019 The Authors. Published for AMER, ABRA \& cE-Bs by e-International Publishing House, Ltd., UK. This is an open access article under the CC BY-NC-ND license (http://creativecommons.org/licenses/bync-nd/4.0/). Peer-review under responsibility of AMER (Association of Malaysian Environment-Behaviour Researchers), ABRA (Association of Behavioural Researchers on Asians) and CE-Bs (Centre for EnvironmentBehaviour Studies), Faculty of Architecture, Planning \& Surveying, Universiti Teknologi MARA, Malaysia.

DOI: https://doi.org/10.21834/jabs.v4i14.339
\end{abstract}




\subsection{Introduction}

The survival of the indigenous Simeulueans in Sumatra and the Moken sea gipsies in the Surin Islands during the Indian Ocean Tsunami in 2004 stole the public attention. It also sparked a new interest over the last few years about the concept of indigenous knowledge. Successful survivals by both tribes showcased how the indigenous communities survived the catastrophic events and dealt with the challenging environmental situations using their century-old knowledge, or the traditional ecological knowledge (TEK) (Meyers \& Watson, 2008; Arunotai, 2008).

TEK is significantly discussed in the context of natural resource management (Houde, 2007; Halim et al., 2012). However, there are now efforts to include this knowledge in the climate change context (Vinyeta \& Lynn, 2013). More notably, the Paris Agreement has recognised indigenous people and their traditional system as part of the solution to climate change. The insight is valuable to foster adaptation and resilience during calamities and to strengthen the community capacity to deal with any disturbances.

\subsection{Literature Review}

TEK refers to an intergenerational knowledge, practice, and belief system on the relationship of living things with one another as well as with their environment. This system may have evolved through adaptive processes (Berkes, 1993). Climate change adaptation, on the other hand, refers to the adjustment and response to the climate change risks and the implementation of appropriate action to reduce the impact of climate change or identification of any opportunities that may arise (Fankhauser, 2017). Indigenous people are responding and adapting to climate changes based on TEK. It gives the community the ability to track changes in their local surroundings and develop local coping strategies. This ability is embedded in the TEK typologies. There are four interrelated TEK categories which are related to the climate change context; namely (1) local knowledge of the environment, (2) customary resource management systems, (3) customary social institutions and networks, and (4) worldview and belief systems (Figure 1).

$$
\text { TYPOLOGY OF TEK }
$$

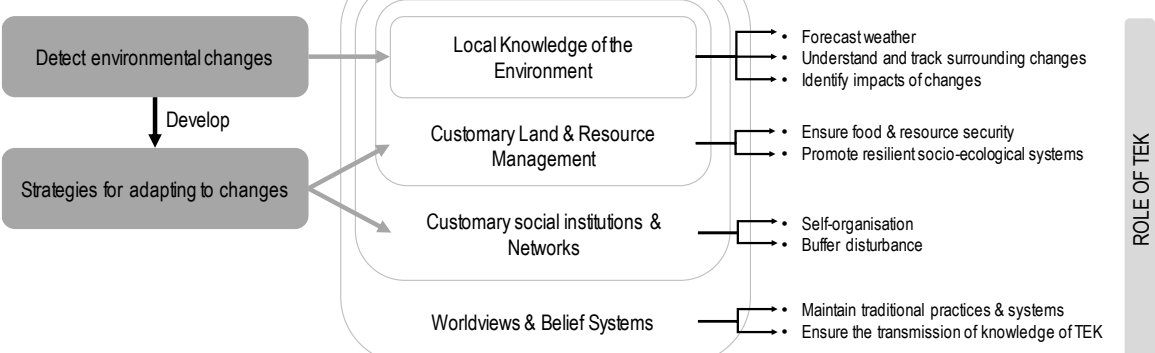

Figure 1: The role of TEK in Climate Change Adaptation (Source: Hosen \& Nakamura, 2019) 
Local knowledge encompasses the understanding of the flora, fauna, landscapes, and soil, including their taxonomy, behaviour, and distribution (Berkes, 2017; Houde, 2007; McMillen et al., 2017). It allows indigenous people to understand the ecosystem functions such as the interactions of animal and plants within it, as well as the biophysical environment, which influences the community behaviour (Freeman, 1992). For example, bioclimatic indicators such as the length of precipitation, sky coverage, wind speed, and the cycle events of periodic plant and animal lives would help the indigenous community to detect changes in weather and season. These elements correspond to their subsistence activities in terms of the timing of agriculture, gathering, hunting, and fishing (e.g. Garay-Barayazarra et al., 2011; Leonard et al., 2013; Kuhnlein et al., 2006; Prober et al., 2011). Given this need for survival, indigenous people are highly responsive to changes in their surroundings.

Customary land and resource management system is the way used by the indigenous people to manage their terrestrial and marine ecosystems which have evolved through adaptive processes (Leonard et al., 2013; McMillen et al., 2014). It helps the community to prepare for any anticipated hazards by modifying practices and developing appropriate strategies. In the case of food security, they will ration, diversify, or store their resources as a precaution so that they have alternative options during unexpected events (Berkes et al., 2000; Gómez-Baggethun et al., 2012). For example, they may enforce some temporary restriction on harvesting, planting, gathering, hunting, or fishing in response to common shortages and to allow the renewal of surrounding ecosystems (Ingty, 2017; McMillen et al., 2014). These practices consequently build their capacity and enhance community resilience.

Customary social institutions and networks are the social attributes in climate change adaptation. It deals with the social cohesion of the community and the ability to cooperate in buffering against climate disturbances besides promoting self-organisation. The key to creating a cohesive society within the indigenous community lies in this facet of TEK. Strong community ties enable them to share assets and resources during the anticipated hazards which in turns, guarantee resource availability and diversity in a time of crises (Agrawal \& Perrin, 2008; Gómez-Baggethun et al., 2012). Good local leadership and institutions are highly essential to avert calamities. They contribute to efficient allocation systems, which results in social cohesion within the community, collective memory, and sustainability (Brown \& Sonwa, 2015; Gómez-Baggethun et al., 2012; Ingty, 2017).

As the final facet of TEK, the worldview and belief systems evolve into the foundation of the whole knowledge system. It becomes a mechanism for intergenerational accumulation and transmission of knowledge (Berkes et al., 2000). The mechanism can be portrayed through various forms such as oral tradition, taboos, ceremonies, festivals, and other traditions. Apart from sustaining the TEK, it also strengthens the social networks within the community and maintains the reciprocity relationship through information and resources exchange. According to Ziegler (2007), they can foster the bond among the exchange parties by creating trust. By building on this relationship, the indigenous community can have guaranteed access to resilient resources during crises.

Despite the relevance of TEK in the climate change context, its documentation is still under-researched, especially in Malaysia. Therefore, the objective of this paper is to explore and document the role of TEK in climate change adaptation using a TEK typology. This 
documentation will help to provide an understanding of how the knowledge systems amassed over generations can continue to evolve and be adopted to improve the communities response to today's climate.

\subsection{Methodology}

\subsection{Study area}

Long Banga is located in the Marudi Division of Sarawak. It is one of the most isolated communities in the upper Baram river, and it lies approximately $373 \mathrm{~km}$ from Marudi, the nearest town. Connected with an unpaved logging road, Long Banga can only be accessed by four-wheeled-drive vehicles. There is a small airport, Long Banga STOLport, which offers twice-a-week flights to Miri and Marudi using DHC-6 Twin Otter. The population of the village is about 500 people, dominated by the Sa'ban community. Agriculture is the main economic activities, and some of the villagers operate small enterprises. Electricity supply is primarily from micro-hydroelectric dam whereas water supply comes from the mountain stream. Currently, there is one primary school (SK Long Banga), a STOLport, a church, and a clinic provided by the government.

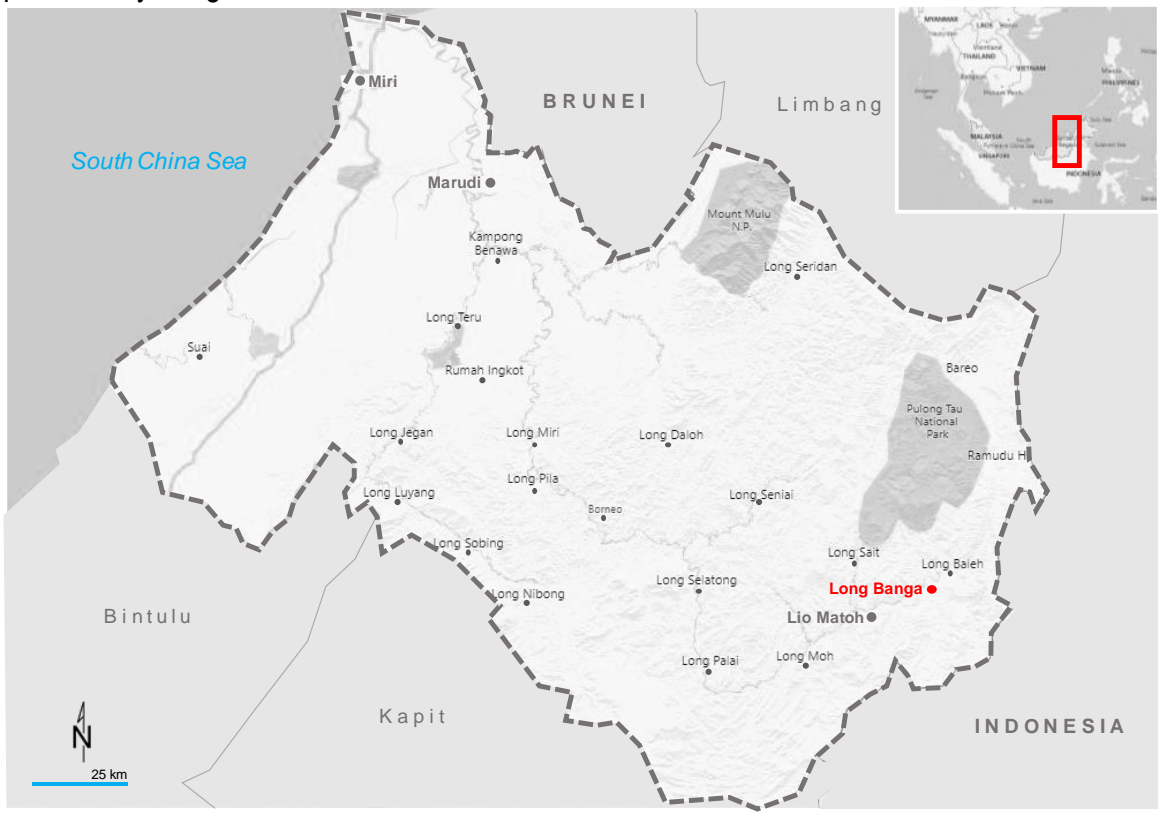

Figure 2: Location of the study area

\subsection{Data collection and analysis}


Data collection was done in January 2019 using interviews with key informants and field observation. The questionnaire did not specifically focus on the term 'climate change', but touched on global environmental changes related to weather and seasons and the impacts on the livelihood of the local community. This technique created a more informal conversation with the villagers and resulted in a more informed dialogue session. The interviewer also asked questions regarding their local strategies to manage the environmental impacts to get a clear view of the role of TEK in climate change adaptation. Ten key informants were identified using the snowball sampling technique. Table 1 shows the demographic profiles of the key informants. Data were then analysed using a qualitative thematic analysis. It is a method used in qualitative research to identify and analyse patterns within data (Cassol et al., 2018).

Table 1: Demographic profiles of the key informants

\begin{tabular}{lc}
\hline Demographic Profile & Key Informant \\
\hline Total Sample & 10 \\
Sex & \\
Male & 6 \\
Female & 4 \\
& \\
Age group & \\
$18-30$ & 0 \\
$31-45$ & 2 \\
$46-65$ & 2 \\
$65+$ & 6 \\
& \\
Education & \\
None & \\
Primary & 6 \\
Secondary & 1 \\
Tertiary & 3 \\
Main Income & 0 \\
Farming & \\
Small business & \\
\hline
\end{tabular}

(Source: Field survey, 2019)

\subsection{Results}

The Sa'ban tribe applied unique ways of adapting to risks of climate change using the TEK. Table 2 summarises the traditional strategies used by the community in Long Banga based on four elements in the TEK typology. 
Table 2: Traditional strategies identified by the Sa'ban tribe for addressing climate variability and change in Long Banga

\begin{tabular}{|c|c|c|}
\hline Typology of TEK & Role of TEK & Result \\
\hline $\begin{array}{l}\text { Local knowledge of the } \\
\text { environment }\end{array}$ & $\begin{array}{l}\text { - } \text { Forecast weather } \\
\text { - Understand and track } \\
\text { surrounding changes } \\
\text { - Identify the impact of } \\
\text { changes }\end{array}$ & $\begin{array}{l}\text { - Bioclimatic indicators: } \\
\text { "Teng" moon in the lunar cycle } \\
\text { - Changes observed: } \\
\text { Increase in temperature } \\
\text { Uncertain weather condition } \\
\text { - Effects of changes: } \\
\text { Erratic rainfall } \\
\text { Drought events } \\
\text { Wildfires }\end{array}$ \\
\hline $\begin{array}{l}\text { Customary land and } \\
\text { resource management }\end{array}$ & $\begin{array}{l}\text { - Ensure food and } \\
\text { resource security } \\
\text { - Promote resilient } \\
\text { socio-ecological } \\
\text { systems }\end{array}$ & $\begin{array}{l}\text { - Shifting cultivation of Padi Iraang } \\
\text { - Storage of resources in Paau Padi } \\
\text { - Diversification of resource: Éra' } \\
\text { - Community forest }\end{array}$ \\
\hline $\begin{array}{l}\text { Customary social } \\
\text { institutions and networks }\end{array}$ & $\begin{array}{l}\text { - Self-organisation } \\
\text { - Buffer disturbance }\end{array}$ & $\begin{array}{l}\text { - Cultural philosophy: Si'sawai, Si'hnau, } \\
\text { Si'lawai } \\
\text { - Community pooling: Ledu' } \\
\text { - Community leader: the Lún Rah Lem } \\
\text { Awéeng } \\
\text { - Church institution: Maa' Tempún and } \\
\text { their Mah Maa'Tempún }\end{array}$ \\
\hline $\begin{array}{l}\text { Worldviews and belief } \\
\text { systems }\end{array}$ & $\begin{array}{l}\text { - Maintain traditional } \\
\text { practices and } \\
\text { systems } \\
\text { - Ensure the } \\
\text { transmission of } \\
\text { knowledge of TEK }\end{array}$ & $\begin{array}{l}\text { - Madei' practice } \\
\text { - Sembayaang (before harvest } \\
\text { ceremony) } \\
\text { - Ngkui (after harvest festival) }\end{array}$ \\
\hline
\end{tabular}

(Source: Field survey, 2019)

\subsection{Local knowledge of the environment}

Understanding change in the local surroundings is essential for the Sa'ban tribe to manage their subsistence activities, especially rain-fed agriculture, hunting, and fishing. Careful observation of the climatic factors such as rainfall and dry day is essential as they affect local livelihoods. Traditionally, their annual planting calendar consists of two seasons; the "wet season' which is from October to February characterised by heavy precipitation and the 'dry season' from March to September with drier and higher temperature. According to the interview with the Sa'ban, they observed significant changes in the weather and seasonal patterns. The tribe noted as follows:

"...what we observe these days, the weather is uncertain. In the previous time, it was fixed. From March to September it is the dry season, less rain. The month of October and 
above, there is a lot of rain. But now, it is uncertain..."

These changes consequently affect the Sa'ban staple food, 'padi iraang', a Sa'banese word that translates as 'upland rice'. The agronomic practice of the 'padi iraang' is different than that of the wet rice farming whereby its cultivation is heavily dependent on both seasons. For 'padi iraang', the dry season is the best time for land preparation for the next planting season whereas the wet season with heavy rain provides perfect conditions for the rice to grow. In the dry season, land clearance, which involves cutting down the trees and grass, is carried out. The area is then left to dry for about a month before burning events are performed to clear the entire place. Therefore, the best time for this practice is during the dry season. Towards the end of the dry season in August, the local community will start to dibble the land for seed sowing. The seeds will then get continuous water supply from the rain during the wet season for growth.

One of the bioclimatic indicators that are utilised to indicate the right time to start the dibble sowing is by observing the lunar cycle or the phases of the moon. According to the villagers, when they see the 'Teng' moon, or the 'first quarter moon' during the night in August, they will start the dibble sowing the next day. According to them, the moon shape indicates that rainfall is near and that they should begin to plant the seed. The villagers noted this:

"...we will search for the moon, the Teng. If we see the Teng, we can start to plant the rice. For example, if we see the Teng tonight, tomorrow we will start the dibble sowing within one week until we finish. The rice will grow very well..."

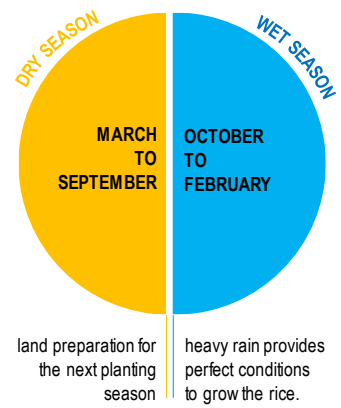

Figure 3: Traditional calendar of Sa'ban

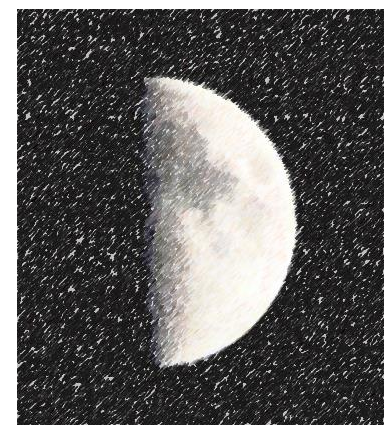

Figure 4: Shape of the 'Teng' moon

However, this indicator is no longer reliable due to the shifting weather and seasons. Thus, this affects their food production and supply. There are abrupt variations to the rainfall; sometimes it is plentiful at an unexpected time, sometimes it is very low for an extended period. This unpredictable rainfall pattern not only disturbs the rice but other activities such as fishing. For instance, the villager noted the following:

"...nowadays, the uncertain weather and season conditions affect us in some ways. If it is too hot, our crops will not grow well because they need water. They grow but not much. On the other hand, if there is too much rain, people cannot go to work on the farm. If we want 
to go fish in the river, also it is difficult due to the rapid flow of the water..."

Another significant change that the tribe observed is the increase in the surrounding temperature. According to the community, the weather is much warmer than it used to be. One of the villagers noted the following:

"...the temperature of this area has changed. A lot of changes compared to the previous time. Last time it was not as hot as this. Now it is scorching. It is weird because we live near the jungle, it was supposed to be cooler because we have many trees..."

The hotter and drier season consequently led to droughts. Unfortunately, prolonged droughts have caused a bigger disaster in the form of wildfires. During the tragedy, the fire burnt the surrounding virgin forest in Long Banga and spread as far as $17 \mathrm{~km}$ within the soil to Lio Matoh. Due to the prolonged dry spell, the wildfire event lasted for two to three months. Almost all the crops and resources in the forest that the tribe depended heavily upon were burnt away, causing significant loss to the villagers. The villager noted as follow:

"...we are afraid that the droughts will cause the wildfires like what happened previously. Last time, there was a long dry spell. The wildfire spread from Long Banga to Lio Matoh. First, the Long Banga area and then to Baram River and then to Lio Matoh. It lasted for months, almost two to three months..."

"...during the wildfires, all the crops of the villagers were burnt. It was hard to control the fire. All the fruits were burnt. The virgin jungle was also burnt. The fire was caused by drought..."

Uncertain weather and seasonal patterns, increase in surrounding temperature, drought and wildfire events in the past have resulted in a significant impact on the livelihood of the tribe. These factors also undermined food security. Therefore, the community members have learned from the disasters and are now better in managing their resources to ensure that food is always available all year round. The next section explains these practices.

\subsection{Customary land and resource management}

Climate change poses threats to the Sa'ban tribe that is heavily dependent on the natural resources and monsoon climate for their agricultural practices. However, having lived in an isolated region facing many years of extreme environmental challenges have prepared them to handle any anticipated hazards. Due to unpredictable weather in recent times, they have become more careful to ensure that resources are available all year round through their traditional harvesting practices, land, and resource management.

For hundreds of years, rice has been the staple food for the Sa'ban. The cultivation of 'padi iraang' is a Sa'ban farming tradition that is passed from generations to maintain sufficient rice production every year. Compared to the wet rice farming, the 'padi iraang' only grows on dry soil and upland terrain. The indigenous technology applied in the plantation of 'padi iraang' is shifting cultivation. The basic concept of this agricultural technique is the rotation of a long season of fallow followed by a short season of farming. It also involves a repeated shift of fields and the use of fire to remove natural vegetation (Erni, 2008). The method begins with 'temaraa" (cutting down trees and other woody plants) and 'lemdiek' (slashing the undergrowth). The area will then be left to dry before 'ntueng'; the burning of dried vegetation takes place. This process helps to create nutrient-rich ashes that improve 
the soil fertility and to eliminate weed and pest temporarily from the area. The tribe will start the seed sowing right before the wet season arrives. Once the rice is matured, it will be harvested. In the next planting season, the same cycle is repeated in other fields. The empty field, on the other hand, is left to rest for four to five years, allowing for regeneration of vegetation that will become trees. The villagers noted this:

"...we do not use any fertiliser. Everything is natural. To ensure that the soil is fertile and the rice grows well, we will shift the field from one place to another every planting season. We only use the same field for a maximum of two times in a row. Because for the 'padi iraang', if you cultivate it at the same place continuously, the yield is not much. That is why we shift from one place to another..."

"...for the 'padi iraang', we burn the dried vegetation, and the ashes become the fertiliser. The 'padi iraang' plantation will shift from one place to another. For example, this year we do it over here, next year we change to another place. We wait until the trees grow for a few years. After about five years, we will do it again there. Every year the plantation site of 'padi iraang' will shift place. We can only cultivate the same land for two times. If we do it three or four times, the soil will not fertile anymore..."

The Sa'ban claimed that through this method, the soil fertility is maintained persistently for years, and the rice will grow well and produce surplus yield. The tribe then keep the surplus in the 'paau padi', or the paddy store, to ensure that they will have a continuous supply of food even when disaster strikes. Thus, this relieves any food scarcity during times of crises. The villagers noted as follows:

"...we have a paddy store, 'paau padi'. The 'paau padi' is full of harvested rice. I have a lot of rice inside the 'pauu padi'. It was from three years back. Also, two years back. And the latest was last year harvest which is still available. We keep the stock. If the harvest is not good, we still have the stock. For example, this year, our harvest was quite poor due to drought. But we still have the harvest from the last few years which were very good. Our 'paau padi' is full during those seasons..."

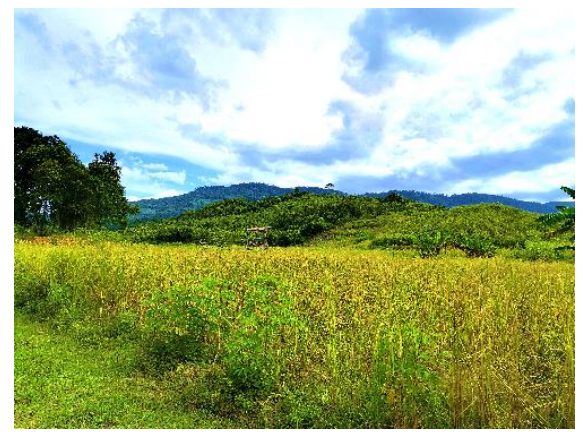

Figure 5: The 'padi iraang' Source: Field survey, 2019

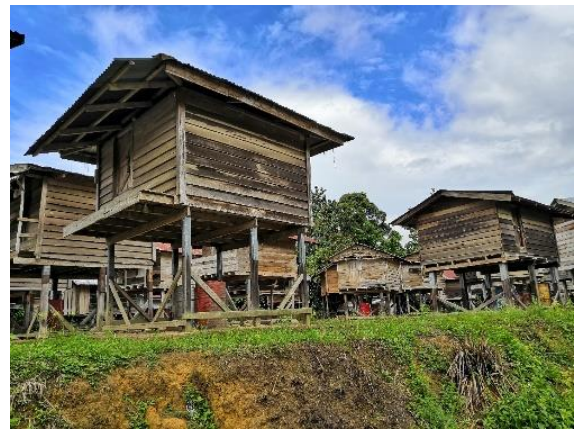

Figure 6: The 'paau padi' for rice storage Source: Field survey, 2019

Apart from 'padi iraang', every family establishes an 'éra'. It is an integrated home garden 
characterised by a traditional land use system where they grow numerous species of plants as their secondary crop. Some examples of crops in their backyards are bananas, sweet potato, manioc, other vegetables, and fruits. Most of these crops are fairly resistant to drought. Sometimes, the home garden also holds other food varieties such as poultry, livestock, and fish. Occasionally, the villagers use the old fallow field as their era to plant other secondary crops such as maize and pumpkin to maximise their food security. The villagers noted as follow:

"...sometimes, we plant pumpkin, corn, and other crops on the fallow fields. But if you do not want to use the land for other things, just let it be. It will become bushes. For example, small trees have grown now. In the next four to five years, the trees will mature. Then we will repeat the process..."

Diversified agroecosystems help the tribe to adapt to climate extremes such as droughts and wildfires. If other resources are damaged, there are still other available food supply. This was proven when the largest wildfires happened in the 1990s and burned all the 'padi iraang' and resources in the forests such as wild fruits and vegetables. Luckily their 'éra' and 'paau padi' were not affected; thus, the food resources were secured. The villager noted this:

"...last time during the wildfires, all our crops, the 'padi iraang' were burnt down. It was hard to control the fire. All the fruits in the jungle were burnt. Luckily our 'éra' in our backyard did not burn during the incidence. The ones that were burnt were the 'plueng raal' (primary forest) and 'amuep' (secondary forest) ..."

"...fortunately our 'paau padi' did not burn. Because we protect them from fire. If they were burnt during the incidence, it means disaster to us. What are we going to eat then? ..."
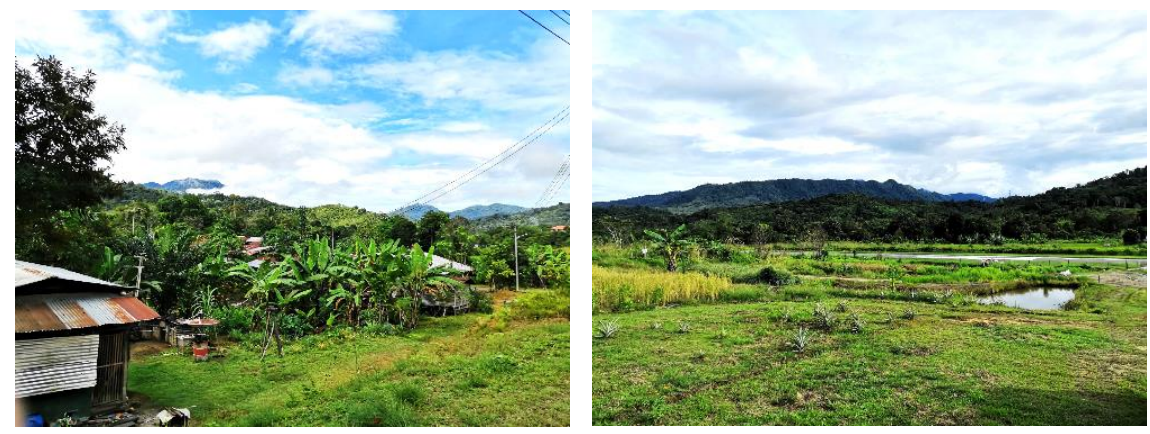

Figure 7: Integrated home-garden or the 'éra'

Source: Field survey, 2019

Besides, the Sa'ban has a community forest reserve that is conserved and protected from any logging activities. The conservation effort helps to maintain the ecosystem integrity, which allows the buffering local climate to reduce the risks and impacts from extreme events. Moreover, the community forest reserve also supports other essential ecosystem supplies which provide them with water, wild meat, fish, and traditional medicine. The villager notes this: 
"...in the Long Banga area, we have a reserve forest that nobody can disturb. We reserve and conserve the area to avoid the loss of our forest. We are afraid that if all the trees are cut, we do not have any place for hunting anymore. Our water supply will be depleted. In fact, we depend on the forest for traditional medicine. If we do not protect it, it will be hard for us..."

\subsection{Customary social networks and institutions}

The ability to act collectively determines the capacity of a society to adapt (Adger, 2003). The Sa'ban highlighted their tribe philosophy, the 'Si'sawai, Si'hnau, Si'lawai', as the root of their social strategies in building adaptive capacity to face environmental challenges. Carrying the meaning of "one heart, one mind, and one goal", this philosophy unites and strengthens the kinship of the community. The tribe noted that it enables collective action and reciprocity wherever they are, especially during hard times. The villager stated the following:

“...'si'sawai, si'hnau, sillawai'. It means one heart, one mind, and one goal. As an identity and philosophy of the Sa'ban, it should be in everyone's heart so that it will be practised wherever they are. Because it unites us and also strengthens our kinship. We are grateful to have the local wisdom..."

For example, they work together to protect their village when wildfires struck them a few years ago. The villager recalled the experience as follow:

"...because people love the trees, the forest, and the village, we fight the wildfires together. We brought the fire extinguishers, the whole village. Some put out the fire over here, and some did it over there. Some protected our 'paau padi'. The village keeper beat the gong to inform the villagers about the hazard..."

They also perform collective action during the planting season because the cultivation of 'padi iraang' is strenuous work, and it needs a significant workforce. They will decide the dates to work on the field together. For instance, the times to cut down the trees, to do the harvesting and other activities related to the 'padi iraang'. Moreover, the Sa'ban practises "ledu", a type of community pooling action meant to help one in needs during crises. According to them, the whole community will help those who experience food shortages due to drought or other disasters by sharing resources and labour. The tribe member mentioned the following:

"...if, one of us in the Sa'ban community is in trouble; we will help him. For example, everybody is working on the farm, but then someone's farm gets hit by disaster, no food for him, we will help. We call this practice as "ledu". It also happens when somebody passed away in the village. We will visit the family. We will bring food to the family..."

Additionally, the Lún Rah Lem Awéeng or the headman is the respected community chief, and he is the point of reference before they make any decision. He also leads the implementation of the values discussed above, besides driving collective actions and managing conflicts. The villager noted this:

"...to strengthen our community ties, our chief, the Lún Rah Lem Awéeng does that. He is the one who will gather everyone to do everything together..."

Another institution that helps the community to self-organise and buffers against disturbance is the Maa' Tempún or the church. Remarkably, it owns a rice farm (Mah Maa' Tempún) which aims to help those who run out of rice due to a bad harvest year. Through 
this farm, the community will work together on the field in all respects, and the yield produced from the farm is given to those in need as a loan. This cooperation enhances unity within the community and provides insurance against food crises. The community noted the following: "...during Sunday prayer in the Church, they will announce, for example, during this date we will do some work in the church farm for this person. So, everybody will go to the farm and work together..."

\subsection{Worldview and belief systems}

The worldview and belief systems help the Sa'ban to pass the knowledge from generations to generations. In their community, the transfer of knowledge starts from the family unit through 'madei", a session to advise and to demonstrate in a practical sense. In this practice, the older folks will give counsel to the youngster about the importance of their traditions. 'Madei" can take place in different locations, either during dinner or lunchtime when everyone in the family gathers. It can also take place on the farm when they bring along their children to teach them about traditional farming and how to secure food resources. The villager noted this as follow:

"...for the Sa'ban, parents and older folks hold the responsibility to advise and teach the children about our tradition. It can take place during our family gathering, lunch, or dinner time. For example, our children, our grandchildren must know and learn about 'padi iraang'. In the past, we brought the children to the farm. We do not want to lose our tradition..."

"...when I was small I followed my parents to the farm and into the jungle for hunting. That is why until now, I can do the farming and hunting myself. I also learned from my parents to prepare for food shortages, especially using the 'paau padi'. It was taught by our ancestors that everyone who does farming must have the 'paau padi'. The structure of the 'paau padi' is high, about 7 to 8 feet above the ground. The body of the 'pauu padi' is made from wood and covered by a layer of zinc or plastic. This design could prevent rats and other unexpected hazards. With this 'paau padi' we will secure our food resources for years..."

Moreover, social functions such as ceremonies and festivals play essential roles in the knowledge transmission and establishment of strong social cohesion within the community. Before the seed sowing, they will perform the 'Sembayaang' ceremony in the church to request for good harvest and avoidance of hazards. After the harvest, they will celebrate 'Ngkui', a Sa'ban after-harvest festival to celebrate the harvested rice and also to express their gratitude for the excellent harvest. In both events, the community gathers and learns about their culture as well as share information and resources. Consequently, it strengthens the reciprocity relationship that they can rely on when disaster strikes. The community noted the following:

"...usually the ceremonies and festivals are our tradition to build relationship among us. Our culture is not the same as urban dwellers. We have ceremonies before we start the planting and also festival after the harvesting. During these events, we can meet and talk to our friends and relatives. We eat, we drink, we do 'ngajat' (traditional dance), we do everything together. And during this time, the young will get advice from the older folks..." 


\subsection{Discussion}

The results revealed the application of TEK in the Sa'ban way of life. The first facet of TEK helps the tribe to detect changes in their surroundings. Significant changes that they experienced include the shifting in weather and seasons with more erratic rainfall and an increase in the temperature in recent times. It also exposes the vulnerability of the tribe to droughts and wildfire events. A significant finding is that the bioclimatic indicators that were used formerly to manage their daily lives are now out of sync. In response to these climatic challenges, the tribe manages their land and resources using the second facet of the TEK. They practice traditional long-fallow shifting cultivation for their upland rice, which benefits both the community and biodiversity system. Their agricultural lands are highly diverse; characterised by a mosaic of vegetation including home gardens, fallow land, annual crops, natural forest, and community forest. This diversity has now become the central element in their adaptation strategies to climate change, which helps to spread risks across space and time. The method of storing stocks has also made them more resilient to climate stresses. In the third facet of TEK, the tribe philosophy becomes the basis of their social network that promotes social cohesion. More notably, the headman and the Church institution oil the wheels for the foundation of the reciprocity network among the community, which is vital to promote collective actions in response to climate difficulties. This is vital to reduce vulnerabilities. Finally, the last facet of TEK hold the three elements together and shows how knowledge transmission from generations to generations occur through ceremonies and festivals. Older folks are vital knowledge holders which command a high level of respect from the community.

However, the tribe expresses their concerns regarding losing the TEK. Many young people have migrated to urban areas for studying and working, thus leaving their parents to work in traditional farming on their own. Due to the changes in lifestyle and modernisation, not many young people are interested in living in an isolated village, though they will come back for festivals annually. Furthermore, the tribe is also worried about the continuous deforestation by the logging company which may impact the forest resources they depend on. Deforestation also decreases the number of trees that helps to reduce carbon dioxide levels, thus increasing the severity of the impact of climate change on the local community.

\subsection{Conclusion}

For hundreds of years, the Sa'ban tribe has lived in harsh environments, thus enabling them to cope with environmental extremes. This research proves that TEK helps them to track changes and provides a method for them to build adaptive capacity in the face of climate change. TEK is a practical tool to adapt in the face of climate risks and vulnerabilities; thus the community-based adaptation of this tool should be promoted. In this time and age, this knowledge system needs further support from science-based knowledge and modern technologies. Finally, policymakers and practitioners should consider integrating TEK into local planning and policy in Malaysia to optimise the use of this knowledge system to adapt to climate change. 


\section{Acknowledgement}

We would like to thank all the key informants in the Long Banga village, Sarawak, who had participated in the interview and contribute to the success of this study.

\section{References}

Adger, W. N., (2003). Social Capital, Collective Action, and Adaptation to Climate Change. Economic Geography, 79 (4), 387-404

Agrawal, A., and Perrin, N. (2008). Climate adaptation, Local Institutions and Rural Livelihoods. IFRI Working Paper (Vol. W081-6).

Arunotai, N., (2008). Saved by an Old Legend and a Keen Observation: The Case of Moken Sea Nomads in Thailand. in Indigenous Knowledge for Disaster Risk Reduction: Good Practices and Lessons Learned from Experiences in the Asia-Pacific Region. Bangkok: UNISDR.

Berkes, F., (1993). Traditional ecological knowledge in perspective. Traditional Ecological Knowledge: Concepts and Cases, J.T. Inglis, Ed., Canadian Museum of Nature/International Development Research Centre, International Program on Traditional Ecological Knowledge International Development Research Centre, 1-9.

Berkes, F., Colding, J., and Folke, C., (2000) Rediscovery of Traditional Ecological Knowledge as Adaptive Management. Ecological Applications, Volume 10 (5), 1251-1262.

Berkes, F., (2017). Sacred Ecology (Fourth). New York: Routledge.

Brown, H. C. P., \& Sonwa, D. J., (2015). Rural local institutions and climate change adaptation in forest communities in Cameroon. Ecology and Society, 20 (2), 6.

Cassol, H., Charland-verville, V., \& Bragard, I., (2018) Qualitative thematic analysis of the phenomenology of neardeath experiences. Plos One, 13 (2), 1-14.

Erni, C., (2008). The Concept of Indigenous Peoples in Asia. A Resource Book. Copenhagen/Chiang Mai: IWGIA and AIPP European Commission.

Fankhauser, S., (2017). Adaptation to Climate Change. Annual Review of Resource Economics, 9, 209-230

Freeman, M. M. R., (1992). The Nature and Utility of Traditional Ecological Knowledge. Northern Perspectives, 20 (1), 9-12.

Garay-Barayazarra, G. and Puri, R. K., (2011). Smelling the monsoon: Senses and traditional weather forecasting knowledge among the Kenyah Badeng farmers of Sarawak, Malaysia. Indian Journal of Traditional Knowledge, 10 (1), 21-30.

Gómez-Baggethun, E., Reyes-García, V., Olsson, P., \& Montes, C., (2012) Traditional ecological knowledge and community resilience to environmental extremes: A case study in Doñana, SW Spain. Global Environmental Change, 22 (3), 640-650.

Halim, A. A., Jawan, J. A., Ismail, S. R., Othman, N., and Ibrahim, N. N., (2012). Indigenous Knowledge and Biodiversity Conservation in Sabah, Malaysia. International Journal of Social Science and Humanity, 2(2), 159-163.

Hosen, N \& Nakamura, H., (2019). Conceptualising the Role of Traditional Ecological Knowledge (TEK) in Climate Change Adaptation. The 3rd International Conference on Climate Change 2019, 1-9. 
Houde, N., (2007). The six faces of traditional ecological knowledge: Challenges and opportunities for Canadian comanagement arrangements. Ecology and Society, 12(2), 34.

Ingty, T., (2017). High mountain communities and climate change: adaptation, traditional ecological knowledge, and institutions. Climatic Change, 145(1-2), 41-55.

Kuhnlein, H., Erasmus, B., Creed-Kanashiro, H., Englberger, L., Okeke, C., Turner, N., ... Bhattacharjee, L., (2006) Indigenous peoples' food systems for health: Finding interventions that work. Public Health Nutrition, 9 (8), 10131019.

Leonard, S., Parsons, M., Olawsky, K., and Kofod, F., (2013). The role of culture and traditional knowledge in climate change adaptation: Insights from East Kimberley, Australia. Global Environmental Change, 23(3), 623-632.

McMillen, H. L., Ticktin, T., Friedlander, A., Jupiter, S. D., Thaman, R., Campbell, J., ... Orcherton, D. F., (2014). Small islands, valuable insights: Systems of customary resource use and resilience to climate change in the Pacific. Ecology and Society, 19(4).

McMillen, H., Ticktin, T., and Springer, H. K., (2017). The future is behind us: traditional ecological knowledge and resilience over time on Hawai'i Island. Regional Environmental Change, 17(2), 579-592.

Meyers, K. \& Watson, P., (2008). Legend, Rltual and Architecture on the Ring of Fire. in Indigenous Knowledge for Disaster Risk Reduction: Good Practices and Lessons Learned from Experiences in the Asia-Pacific Region. UNISDR: Bangkok.Prober et al., 2011

Vinyeta, K., \& Lynn, K., (2013). Exploring the Role of Traditional Ecological Knowledge in Climate Change Initiatives. Gen. Tech. Rep. PNW-GTR-879. Portland, OR: U.S. Department of Agriculture, Forest Service, Pacific Northwest Research Station

Ziegler, R., (2007). The Kula Ring of Bronislaw Malinowski: A simulation Model of the Co-Evolution of an Economic and Ceremonial Exchange System. Review of European Studies, 4(1). 